\title{
LOS ANIMALES DE ZARATUSTRA: HEIDEGGER Y NIETZSCHE EN TORNO A LA CUESTIÓN DE LO VIVIENTE ANIMAL
}

\author{
Zarathustra's Animals: Heidegger and Nietzsche \\ on the Question of Living Animal
}

\author{
Mónica B. Cragnolini
}

Universidad de Buenos Aires

Resumen: El lugar de la animalidad en la obra de Nietzsche y, sobre todo en Así habló Zaratustra, es un punto clave para comprender el tránsito hacia la figura del Übermensch. El acercamiento heideggeriano a esta cuestión se encuadra en el marco general de la interpretación del pensador que profundiza el nihilismo y, con el mismo, la metafísica representativa dominadora de la tierra. Este artículo señala algunos de los aspectos problemáticos de dicha interpretación e intenta mostrar la importancia de otro modo de afrontar la cuestión del animal en Nietzsche.

Palabras clave: animalidad - sujeto - ultrahombre

ABSTRACT: The place of animality in the work of Nietzsche, mainly in Thus Spoke Zaratus$t r a$, is a key point to understand the path toward the Uebermensch. Heidegger's approach to this question in Nietzsche must be thought in the line of the interpretation of a thinker that deepens nihilism, and of the representative metaphysics that dominates all the earth. This paper examines some problematic aspects of this interpretation, and tries to show the importance of another way to think the notion of animal in Nietzsche.

Keywords: animality - subject - overman

El lugar de la animalidad en el pensamiento de Nietzsche y, sobre todo en Así habló Zaratustra, es un punto clave para comprender el tránsito hacia la figura del ultrahombre. El acercamiento heideggeriano a esta cuestión se encuadra en el marco general de la interpretación del pensador que profundiza el nihilismo y, con el mismo, la metafísica representativa dominadora de la tierra.

Señalaré, en este artículo, algunos de los aspectos problemáticos de dicha interpretación, e intentaré mostrar la importancia de otro modo de afrontar la cuestión del animal en Nietzsche. En este sentido, me detendré en Así habló Zaratustra, texto en el cual el animal, más allá de la constantemente aludida presencia del águila y de la serpiente, ocupa un lugar que debe ser analizado en diferentes perspectivas, para captar algunas de las posibilidades que abre para el pensamiento contemporáneo la cuestión de «otro modo de ser»: el modo de ser de lo viviente no humano. 


\section{CARACTERÍSTICAS GENERALES DE LA INTERPRETACIÓN DE HEIDEGGER}

Si bien no existe «una» interpretación heideggeriana del pensamiento de Nietzsche, se suele admitir que «la» interpretación por excelencia es la que corresponde a los cursos de 1936-1946, que se encuentran en los dos volúmenes del Nietzsche. Esta caracterización de «la» interpretación por excelencia no se relaciona solamente con el hecho de que los cursos de esa época estuvieron destinados a este autor, sino también con una razón más abarcadora, por así decir. Y es que en estos cursos también se «diseña» la interpretación «ontoteológica» de la historia de la filosofía, con el lugar importantísimo que le queda destinado a Nietzsche en la misma. Es decir, Nietzsche es aquí no solamente el pensador cuyo estudio es objeto de los cursos, sino también el pivote para la interpretación del cumplimiento de la metafísica de la subjetividad y la posibilidad de comprensión de la manifestación del ser en términos del Gestell (lo que coincide con su mayor ocultamiento). El pensador del eterno retorno se convierte en la clave para entender la época de la tecnociencia y del avance de la devastación de la tierra en nombre de la voluntad de dominio encarnada en la razón tecnocientífica. Sin embargo, existen diferencias entre los dos volúmenes del Nietzsche, y son claramente los cursos testimoniados en el volumen II los que se desarrollan de manera más comprometida con el contexto de esta interpretación. Los cursos de los años 1936-1937 (Nietzsche I) nos presentan un Nietzsche inversor del platonismo, pero alentando también, si bien en forma difusa, una posibilidad de transformación de esta simple inversión ${ }^{1}$.

Otros textos que deben ser ubicados en la misma línea del segundo volumen del Nietzsche son los que se encuentran en Holzwege («Gott ist tot» y «Die Zeit des Weltbildes»), que remiten nuevamente a la figura del pensador del eterno retorno como profundizador de la metafísica de la subjetividad. En este sentido, son particularmente notables los «Addenda» a «Die Zeit des Weltbildes» ${ }^{2}$. Was heisst denken (1950) permite pensar en otra etapa interpretativa, en la que el ultrahombre ya no es considerado exclusivamente en la línea de la metafísica de la subjetividad. ${ }^{3}$ Ya no está presente en esta obra el carácter calculador-representativo de la figura del ultrahombre, sino que precisamente el mismo es pensado en oposición a esta idea como un tipo de hombre para el que "caduca» lo cuantitativo. Sin embargo, en la conferencia "Quién es el Zaratustra de Nietzsche», de 1954, y como muy bien lo ha mostrado Remedios Ávila, ${ }^{4}$ Zaratustra, como maestro de la liberación del espíritu de venganza, sigue siendo interpretado por Heidegger en la línea del nihilismo y de la metafísica.

Me abocaré en el tramo siguiente a la interpretación de la cuestión del animal en un trabajo del primer volumen del Nietzsche, pero teniendo en cuenta el contexto interpretativo de los dos volúmenes.

1. Recordemos, de paso, que Nietzsche ya está presente en Sein und Zeit, en el $\mathbb{\$} 76$, cuando, refiriéndose a la Segunda intempestiva, Heidegger señala que Nietzsche comprendía más cosas de las que daba a conocer.

2. En M. Heidegger, Holzwege, Pfullingen: Neske, 1956. Cf. especialmente las notas 4, 6, 8 y 9. Es en esta última nota donde es posible entender el lazo necesario entre la noción de representación (Vor-stellung) y el Ge-stell, y a Nietzsche como haciendo evidente lo que estaba implícito en la cogitatio: la co-agitatio.

3. En este sentido, véase el artículo de M. Haar, «Heidegger: une lecture ambivalente»: Magazine littéraire 298 (abril de 1992), 95-96.

4. R. Ávila, El desafío del nibilismo, Madrid: Trotta, 2005, pp. 224-245. 


\section{EL LUGAR DE LOS ANIMALES DE ZARATUSTRA EN LOS CURSOS SOBRE NIETZSCHE}

En el curso sobre «El eterno retorno de lo mismo» ${ }^{5}$ Heidegger se refiere a los animales de Zaratustra. Su discurso oscila entre una aproximación de los mismos a lo humano, demasiado humano, y una cercanía - no suficientemente desarrollada - a la soledad zarathustriana. Heidegger no se pregunta aquí por la cuestión de la «animalidad en sí» ${ }^{6}$, sino que da por sentado un cierto lugar de lo animal que no cuestiona (el mismo que le ha asignado toda la tradición antropocéntrica), a pesar de que el protagonismo que adquieren los animales en los capítulos del Zaratustra que comenta ameritaba, sin lugar a dudas, un mayor cuestionamiento acerca de qué significa, en la obra de Nietzsche, el «modo de ser animal».

En primer lugar, es necesario recordar que, según Heidegger, Nietzsche piensa en la figura de Zaratustra otro modo de ser diferente del humano que ha existido hasta el momento. ${ }^{7}$ Es cierto que Heidegger realiza una equiparación con el «pensador heroico», sin embargo, acepta que su modo de ser es diferente al del «hombre». ${ }^{8}$ Zaratustra trae una enseñanza, la del eterno retorno, que exige un carácter trágico, carácter que Heidegger define como «el supremo sí al no más extremo». ${ }^{9}$ Es por ello que ningún hombre «actual» (el último hombre) puede pensar en términos de esta idea, ya que la misma implica una «transformación» del modo de ser hombre en el Übermensch. Sin embargo, Heidegger no piensa al Übermensch como un modo de ser que «ya no es hombre» (a pesar del «más allá» implícito en el Über) sino como «hombre transformado». Que Heidegger piensa al Übermensch como «hombre» en el sentido «humanista» del término, es algo que queda claro a partir de la caracterización que realiza de la historia de la metafísica de la subjetividad, en la que la que el pensamiento de Nietzsche aparece como consumación de la misma. En efecto, mientras que el acento de la subjetividad cartesiana estaba puesto en el prefijo Vor del Vorstellen -representar- (el «ante» que implica la relación con el objeto como aquello colocado ante los ojos, y que debe ser retrotraído al ámbito de la conciencia en la misma representación -Vorstellung-—), Heidegger señalará el énfasis Nietzscheano en el stellen que derivará en el Gestell de la tecnociencia. Por ello, de ninguna manera se puede afirmar que en la interpretación heideggeriana el ultrahombre se sustrae a la senda trazada por los humanismos: en el modo de un «superhumanismo», el ultrahombre será el encargado, como «tecnócrata», de colaborar en la desvastación de la tierra y acrecentar, con ello, el nihilismo.

5. «Die ewige Wiederkehr des Gleichen», en Nietzsche, Pfullingen: Neske, 1961, vol. I, pp. 255-472. El Nietzsche se cita en adelante como Nietzsche I y Nietzsche II según el tomo, y cuando se remite a la traducción entre paréntesis, la misma es de Juan Luis Vermal, Nietzsche, Barcelona: Destino, 2000

6. El tema de la animalidad en sí ha sido trabajado por Heidegger en Die Grundbegriffe der Metaphysik. Welt - Endlichkeit - Einsamkeit, en Gesamtausgabe, Frankfurt a. M.: Klostermann, vols. 29 y 30, 1992. Aclaro, de paso, que no habría posibilidad en términos heideggerianos de pensar en sentido estricto «la animalidad en sí», ya que el animal nos resulta ónticamente lo más cercano, pero ontológicamente lo más lejano.

7. Nietzsche I, p. 284 (p. 233)

8. Con esto quiero indicar que se da allí una oscilación entre pensar a Zaratustra como hombre (hombre heroico, pero hombre al fin) y pensarlo de modo diferente al modo de ser «humano».

9. Nietzsche I, p. 284 (p. 233) 
La ubicación del Übermensch en la historia de una metafísica de la subjetividad que acrecienta, en su historia, el aspecto dominador ya presente en el representar, le quita a esta figura Nietzscheana toda posibilidad de indicación de «algo diferente» a lo planteado por los humanismos. Si tenemos presente que en los humanismos el aspecto «animal» de lo humano está representado por la corporalidad, evidentemente el Übermensch, en la interpretación heideggeriana, no puede apuntar a nada diferente con respecto a este tema en relación con dicha tradición. Sin embargo, cabe destacar un problema en que cae la interpretación heideggeriana en este sentido: si el superhombre es la exaltación de la voluntad de poder en su aspecto calculante ${ }^{10}$, no queda claro por qué para Heidegger la figura del mismo es una inversión del concepto de animal rationale a favor de la animalitas. ${ }^{11} \mathrm{Al}$ pensar al Übermensch desde el modelo de la inversión metafísica, pareciera que este esquema genera dos modos de interpretación opuestos en Heidegger. En efecto, si el concepto de «hombre diferente» que piensa Nietzsche debe ser ubicado en la trayectoria dominante de la subjetividad cartesiana exacerbada, entonces la voluntad de poder es ejercicio calculante-dominador ${ }^{12}$, y el Übermensch es un supersujeto tecnócrata, lo que implica un sobredimensionamiento del aspecto racional en la clásica definición del animal rationale. Y Heidegger es muy claro en el sentido de señalar que este dominio que ejerce el Übermensch no es el de la violencia, sino el de la «maquinalización». Ahora bien, si, por otro lado, se afirma que el concepto Nietzscheano implica una «inversión» a favor de la animalitas, existe en esta afirmación algo que merece mayor análisis. Heidegger ha señalado la importancia de sus lecciones en torno a Nietzsche en el intento de desligar su pensamiento de las apropiaciones biologicistas, sin embargo, en este punto, la adjudicación de sobrevaloración de la animalitas parece volver a ubicarlo en dicha senda.

Es decir, si el Übermensch es un animal rationale, en el que el acento se coloca en el aspecto animal (y no en el racional, como lo hizo toda la tradición que Nietzsche critica), ¿̇qué es este «animal», si Heidegger caracteriza al Übermensch como tecnócrata? ¿Qué aspecto del «animal» evidencia el dominio indiscriminado de la tierra? Es más, ¿no incluye el dominio de la tierra también el dominio del animal? ¿Acaso el animal puede convertir la realidad en Bestand? ¿No se necesita para ello cálculo, representación, estrategia, aquellas artes que domina el humano, demasiado humano ${ }^{13}$ (y que domina también para dominar desde ellas al viviente animal)?

En «El eterno retorno de lo mismo y la voluntad de poder», de 1939, Heidegger explicita esta cuestión que indico como problemática de la siguiente manera ${ }^{14}$ : la rationalitas desplegada en el ejercicio calculante de la Wille zur Macht

10. Cf. Nietzsche II, pp. 263 ss. (pp. 213 ss.).

11. He señalado este problema en Nietzsche, camino y demora, Buenos Aires: Eudeba, 1998, pp. 203-204. Es cierto que Heidegger presenta el pensamiento de Nietzsche como «radicalización» de un determinado modo de interpretar al hombre como "animal racional». Pero si la exacerbación del aspecto racional resulta «clara» en su explicitación del carácter calculador de la voluntad de poder, no acontece lo mismo con la cuestión de la animalitas (es decir, no queda claro por qué el Übermensch es una exacerbación de la misma).

12. Nietzsche II, p. 304: «Él es, en tanto sujeto supremo de la subjetividad realizada, el puro ejercicio de la voluntad de poder».

13. Aquí me refiero al «humano» en el concepto que del mismo tienen los humanismos.

14. Cf. Nietzsche II, p. 23 (p. 24). 
da poder a la animalitas que termina por transformarse en brutalitas. Teniendo en cuenta la definición Nietzscheana del hombre como «animal no fijado", Heidegger afirma que el Übermensch sería la fijación de la animalidad, dado el valor que Nietzsche concede al cuerpo. Sin embargo, no queda claro en esta explicitación por qué la tecnociencia sería el ejercicio de una corporalidad que domina el mundo. Al respecto, solamente quisiera señalar que Nietzsche vio claramente que el «yo pienso» y el «yo quiero» son lo mismo ${ }^{15}$ : en ambos casos se trata de un ámbito de representación, sea en el modo del pensamiento, sea en el modo del deseo (habitualmente asociado a la corporalidad). Es decir, para comprender el tránsito al ultrahombre, se hace necesario tener en cuenta que Nietzsche no plantea una «sustitución» de la racionalidad a favor de la animalidad en la figura del Übermensch, y la relación que indica entre el Ich denke cartesiano y el Ich will schopenhaueriano lo testimonia: en ambos casos, se trata de una subjetividad que opera como arkhé, sea en el ámbito de las cogitationes, sea en el ámbito del cuerpo que desea y entonces se «representa» los medios para alcanzar su objeto.

Heidegger también destaca que los animales son el discurso de la soledad de Zaratustra, es decir, en aquellos momentos en que Zaratustra queda solo con su alma, desaparecidos ya los otros hombres, quienes hablan (o parlotean) son los animales. Este es, según mi parecer, un elemento clave para pensar el lugar de la animalidad en el Zaratustra, ya que cada vez que el profeta persa se aleja de los hombres (hombres del mercado, aventureros, navegantes, hombres superiores), vuelven a aparecer sus animales. Al final de la IV parte del Zaratustra, esto se reafirmará aún más con la aparición de «otros» animales (el león y las palomas) que hacen huir a los pretendidos hombres superiores. Indico aquí esta cuestión, que luego retomaré al desarrollar mi interpretación de los animales en la obra, para hacer visible que Heidegger ha hecho evidente este nudo problemático de la relación soledad-animalidad, pero no ha tenido en cuenta la posibilidad de pensar esa animalidad más allá del modelo humanista.

Ahora bien, Heidegger aclara que estos animales «no son animales cualesquie$\mathrm{ra}$, su esencia es una imagen de la esencia del mismo Zaratustra ${ }^{16}$, recalca que son «animales suyos» y, en este sentido, los interpreta como «imágenes» del eterno retorno. Es decir, los animales no «valen» en tanto animales, sino en tanto «imágenes» de otra cosa. Por ello Heidegger se demora en caracterizarlos dentro de lo que podríamos llamar el estilo de la «tradición fabulística», es decir, la tradición de la antropomorfización de los animales a los efectos pedagógicos o de «moraleja» ${ }^{17}$. Con este fin, expone de manera muy detallada qué significarían estos animales en tanto imagen de otra cosa: «el enroscarse y anillarse de la serpiente son un símbolo del anillo del eterno retorno» ${ }^{18}$; "el águila es el animal más orgulloso» ${ }^{19}$, ya que

15. Lo indica claramente en JGB $\mathbb{} 16$ (KSA V 29-30). iY Heidegger señala que Nietzsche no entendió a Descartes!

16. Nietzsche I, p. 298 (p. 245).

17. Me refiero a la larguísima tradición que ha visto a los animales como «imágenes» de cuestiones humanas, tradición que tiene sus puntos más representativos en las fábulas de La Fontaine y de Esopo. Para este punto, véase E. de Fontenay, Le silence des bêtes, La philosophie à l'éprenve de l'animalité, Paris: Fayard, 1998, XI, 3, pp. 365 ss.

18. Nietzsche I, p. 299 (p. 246).

19. Ibid. 
representa «la seguridad de ya-no-confundirse $»^{20}$; «la serpiente es el animal más inteligente ${ }^{21}$, en tanto representa «el dominio sobre la máscara, el no abandonarse (das Sich-nicht-preisgeben) [...] el poder sobre el juego de ser y apariencia» ${ }^{22}$.

Pero, por otra parte, Heidegger también aclara que no son animales domésticos (Haustiere), están ajenos a lo familiar y a lo habitual, y por ello se conectan con la soledad de Zaratustra. Y estar con ellos en la soledad no supone adoptarlos como compañía para soportar la misma, sino el «tener la fuerza de seguir siendo fiel a sí mismo en la cercanía de estos animales y no dejar que se vayan ${ }^{23}$. De alguna manera, podríamos decir que estos animales de la soledad están más cercanos de lo Unheimliches que de lo familiar, de lo peligroso que de la seguridad que podría dar la compañía.

A pesar de ello, a pesar del reconocimiento de la importancia de los animales para el diálogo de Zaratustra con su alma, Heidegger señala que ese diálogo es sólo "parloteo» ${ }^{24}$. Ellos, que le presentan el mundo como jardín, pensado no a la manera epicúrea sino como "rechazo de toda residencia sosegada» ${ }^{25}$, ellos, que con esta idea lo aproximan al concepto de mundo del conocimiento trágico, es decir, no un cosmos sino una «comunidad» en lucha ${ }^{26}$, ellos ... ¿simplemente parlotean? ${ }^{27}$. Para Heidegger, los animales se comportan aquí como hombres, semejantes al enano, hablan simplemente de un tiempo curvo, o meramente describen «lo que pasa cuando todo gira $»^{28}$. Transforman en «cantilena» un pensamiento tan «esencial» como el del eterno retorno, porque la simple idea de que toda va y todo vuelve, genera un estado de indiferencia que obvia la necesidad de la decisión (aquella del pastor que debe morder la cabeza de la serpiente).

Sin embargo, nuevamente los animales parecen alejarse de toda idea de «hombre» (sea enano, sea último hombre, sea epicúreo) cuando convocan a Zaratustra al canto. El canto y la curación deben ir juntos, el canto es lo que anhela el poeta, el creador. Y es entonces cuando los mismos animales reconocen que finaliza el ocaso de Zaratustra. Y Heidegger afirma: «Ahora el orgullo del águila y la inteligencia de la serpiente forman parte de la constitución esencial de Zaratustra $»^{29}$. En otros términos, y más allá de Heidegger, que pone el acento en la cualidad «humana» de los animales, podríamos decir: el ocaso de Zaratustra supone asumir la animalidad, el «animal que es» ${ }^{30}$. Más allá de Heidegger por-

20. Ibid.

21. Nietzsche I, p. 300 (p. 246).

22. Ibid.

23. Nietzsche I, p. 301 (p. 247).

24. Nietzsche I, p. 309 (p. 253).

25. Nietzsche I, p. 306 (p. 251).

26. Me refiero al escrito póstumo de 1882-1884 que cita aquí Heidegger para diferenciar el jardín tranquilo epicúreo de esta idea Nietzscheana, aludiendo a una «nueva forma de comunidad», cf. Nietzsche I, p. 306 (p. 251).

27. De esto los acusa Zaratustra al señalar su insistencia en el aspecto circular del pensamiento del eterno retorno. Mi pregunta se refiere, más allá de esta escena, a todos los diálogos de la soledad de Zaratustra con sus animales.

28. Nietzsche I, pp. 308-309 (pp. 254-255)

29. Nietzsche I, p. 316 (p. 258).

30. Me refiero, por supuesto, a Derrida, L'animal que donc je suis, Paris: Galilée, 2006 (El animal que luego estoy si(gui)endo, trad. de C. de Peretti y C. Rodríguez Marciel, Madrid: Trotta, 2008). 
que, obviamente, él interpreta a los animales no «en tanto» animales, sino como símbolos de algo diferente (y siempre cercano a lo humano).

Pero cuando Heidegger analiza los textos del Nachlaß que remiten al pensamiento del eterno retorno, indica que Nietzsche, en vistas del «mundo en su carácter total $\aleph^{31}$ piensa la totalidad de lo viviente y lo no viviente como conexión entrelazada y en devenir. Y agrega que lo viviente abarca no sólo a animales y vegetales, sino también al hombre. Este mundo, que Nietzsche piensa en la forma de lo viviente y las fuerzas, es tanto fuego como cenizas: ni el fuego podría caracterizar sólo lo viviente, ni las cenizas sólo lo muerto sino que, en un mundo de fuerzas en devenir, las cenizas son fuego. Si Heidegger ha tenido en cuenta esta "comunidad con lo viviente», ¿̇por qué no ha desarrollado en este punto la idea de animalidad y su significación en esta comunidad, más allá de los ya señalados desplazamientos de caracteres animales a lo humano? Tal vez sea esta cuestión de la comunidad como modo del ser-con, como aquello no-pensado por la tradición humanista, lo que es necesario transitar para pensar al ultrahombre.

Por otra parte, es llamativo que Heidegger haya visto como compañía de la soledad de Zaratustra a los animales y no haya indagado más profundamente acerca del lugar de la animalidad en este punto. En los cursos de 1929-1930, dedicados en gran parte a la cuestión del animal ${ }^{32}$, se dice que la filosofía es una conversación a solas del hombre, y la finitud «es el modo fundamental de nuestro ser (die Grundart unseres Seins) " ${ }^{33}$. La finitud debe ser custodiada, y esa custodia (que es nuestra verdadero tornarnos finitos -Verendlichung-) se produce en «aquel retiro a la soledad en el que todo hombre llega por vez primera a la proximidad de lo esencial de todas las cosas, al mundo ${ }^{34}$.

Tal vez, y tomando estas consideraciones de cursos anteriores al Nietzsche, lo que Heidegger podría haber planteado en este punto es qué significa esa presencia de los animales en la soledad, en relación con este concepto indicado de custodia de la finitud. Entonces, los animales dejarían de ser meras «voces de organillo», y tal vez darían la pauta para pensar otra relación con la animalidad, diferente a la que consagraron los humanismos, y cercana a la «comunidad con lo viviente» que el mismo Heidegger enuncia.

\section{OTRA INTERPRETACIÓN DEL ANIMAL EN EL ZARATUSTRA}

Es necesario notar que en «De la visión y del enigma» aparecen otros animales, que no son solamente los que, según Heidegger, son de Zaratustra. Por ejemplo, la serpiente que se le atraganta en la garganta al pastor: es cierto, estamos acostumbrados (porque un discípulo de Zaratustra nos tienta a ello) a interpretarla en el sentido de «símbolo» del nihilismo. Sin embargo, podríamos arriesgar otra interpretación: ¿̇no será que para devenir Übermensch, ya no super-hombre, sino

31. Nietzsche I, p. 342 (p. 279).

32. M. Heidegger, Die Grundbegriffe der Metaphysik. Welt - Endlichkeit - Einsamkeit, cit. (Los conceptos fundamentales de la metafísica. Mundo, finitud, soledad, trad. de A. Ciria, Madrid: Alianza, 2007).

33. M. Heidegger, Die Grundbegriffe der Metaphysik, cit., p. 8 (p. 29).

34. Ibid. 
ultra-hombre, se torna necesario que se nos «atragante» y nos atraviese la animalidad, como un modo diferente de comprenderla?

De alguna manera, podría decirse que toda la cuarta parte del Zaratustra indica, en el tránsito hacia el ultrahombre, un necesario pasaje por la animalidad. En qué consiste este pasaje, más allá de toda interpretación biologicista, es lo que intentaré mostrar en lo que sigue. Para ello, parto de una premisa de carácter metodológico y de otra de carácter hermenéutico.

En primer lugar, considero que la cuarta parte del Zaratustra no es un «mero agregado» o el inicio de una obra diferente de Nietzsche, como han indicado diferentes intérpretes ${ }^{35}$. Esto significa reconocer una especial «necesidad» de esta parte de la obra en relación con las tres partes anteriores, y en ese sentido, desde una lectura del Zaratustra como obra de pasajes y de tránsitos ${ }^{36}$, creo que en esta cuarta parte se manifiesta, en el ocaso del humanismo, el necesario pasaje por la problemática de la animalidad. Si hay un ocaso en la obra, además de los múltiples ocasos de Zaratustra, es el ocaso de Occidente (tierra por excelencia de los ocasos si las hay), íntimamente asociado al «irse al fondo» (Unter-gehen) de los humanismos. En efecto, a lo largo de la obra Zaratustra, que comienza predicando el Übermensch al pueblo, a los últimos hombres, debe realizar un tránsito entre «otros modos de ser» hombre (aventureros, hombre superiores) para, al final del texto, deponer toda esperanza en la «humanidad» (en los modos en que la misma se dé) y quedar, como al inicio de la obra, nuevamente solo, en esa soledad acompañada por los animales. Esto significa, desde el punto de vista hermenéutico, que se podría interpretar toda la cuarta parte del Zaratustra como un largo discurso acerca de la animalidad, y de lo que acontece con la misma cuando el hombre «deja de ser hombre» y prepara la venida del ultrahombre.

No me voy a detener en las consideraciones Nietzscheanas acerca de la animalidad que aparecen en otras obras ${ }^{37}$, pero indicaré algunos puntos a tener

35. Señalo esto sin dejar de tener en cuenta que la obra se publicó como libro «aparte» del resto. Al respecto, E. Fink (Nietzsches Philosophie, Stuttgart: Kohlhammer, 1960) señala que la cuarta parte no logra cumplir su propósito de mostrar la inconmensurabilidad de la grandeza de Zaratustra frente a las otras formas de «hombre», ya que Zaratustra no gana nada de esencial frente a los hombres superiores. R. Machado, que concluye su Zaratustra. Tragédia nietzschiana (Rio de Janeiro: Jorge Zahar, ${ }^{2} 1999$ ) con el análisis de la tercera parte de la obra, señala en p. 153 que la cuarta parte no agrega nada al libro, que permanece inacabado. R. Gooding-Williams (Zaratustra's Dionysian Modernism, Stanford University Press, 2001) sostiene que Más allá del bien y del mal completaría el Zaratustra inconcluso, con la creación de nuevos valores destinados al niño de "Las tres transformaciones" (habida cuenta de la terminación de la cuarta parte en la figura del león, previa a la del niño en el capítulo aludido del Zaratustra). E. Carrasco Pirard (Para leer Así habló Zaratustra de F. Nietzsche, Chile: Editorial Universitaria, 2002, p. 135) señala que la cuarta parte es el comienzo de una obra no escrita y no el final del Zaratustra, y las razones que aduce se relacionan con el carácter inconcluso de la obra, en la que la promesa de la llegada de los hijos de Zaratustra no se cumple. Por su parte, A. Martins («Romantismo e tragicidade no Zaratustra de Nietzsche»: Cadernos Nietzsche 25 [2009], 115-144) interpreta la «necesidad» del IV Zaratustra en términos de la idea del amor fati. Cf. también, entre otros, P. S. Loeb, «The Conclusion of Nietzsche's Zaratustra»: International Studies in Philosophy 32/3 (2000), 137-152.

36. Al respecto, véase mi artículo «De Bactriana y el Urmi a la montaña y el ocaso. A modo de introducción a Así habló Zaratustra»: Revista de Filosofía LV-LVI (2000), 39-56.

37. Remito para ello a mi conferencia «Extraños devenires: una indagación en torno a la problemática de la animalidad en la filosofía Nietzscheana», dictada en el Encuentro México-EspañaBrasil: El retorno de Zaratustra. El pensamiento de Nietzsche frente al mundo contemporáneo, Uni- 
en cuenta para el desarrollo de lo que sigue. En primer lugar, considero que en la filosofía de Nietzsche el animal es una de las figuras de lo extraño, extraño que somos también nosotros mismos (para nosotros mismos) en tanto animales. Por esta razón, que Zaratustra comience la obra «solo» con sus animales, y que termine la obra «solo» con animales, está indicando, según mi parecer, que el camino hacia el ultrahombre debe transitar esa extrañeza que somos en tanto animales, pero en tanto extrañeza (y no, como han hecho los humanismos, como la parte "patológica», y por lo tanto dominable, del hombre en tanto racional). Transitar la animalidad como extrañeza supone no convertir al animal (ni al otro viviente animal, ni al animal en nosotros) en algo que puede ser «asimilado» en los modos del aprovechamiento, del usufructo, de la proyección, o del ejercicio de la violencia hacia el que se considera «inferior» ${ }^{38}$. Los humanismos, al concebir al hombre como «animal racional», han pensado la animalidad en esos modos de relación que suponen siempre un aspecto sacrificial en la relación con lo diferente de lo humano, que es también el animal «en» el hombre. De alguna manera, el «malestar de la cultura» transita por este camino sacrificial, que supone tratar de regularizar el carácter caótico de lo viviente con los medios más cruentos posibles. Lo viviente es lo que debe ser acallado, por eso la «voz» de lo animal es la voz que el humano pareciera que no puede escuchar ${ }^{39}$. Esa voz se silencia, entre otros modos, en la «regularización» que supone el concepto de «instinto animal» con respecto a la vida deviniente.

En la cuarta parte del Zaratustra, el profeta persa se encuentra solo en su caverna, luego de varios años, y son sus animales los que, de manera insistente, le vuelven a plantear la necesidad de seguir su camino en la búsqueda de discípulos. Los animales «se colocan delante de él» de manera reiterativa, recordándole que él no aspira a «su felicidad» sino a su obra, pero Zaratustra, que apela a la llegada de los hombres superiores, acota también que aguarda los signos para «hundirse en su ocaso». Esos signos habían sido anunciados en la tercera parte de la obra como la bandada de palomas y el león riente ${ }^{40}$. De modo tal que pareciera que la transformación (el hundirse en su ocaso) implica el advenimiento de estos signos, que remiten al modo de ser del viviente animal.

Zaratustra decide realizar una ofrenda, un sacrificio («Das Honig Opfer») que intenta atraer a los hombres superiores, sus posibles discípulos. A lo largo de esta cuarta parte, se hace referencia a varios sacrificios de la vida; acontece una ceremonia en la que se adora a un asno, y se finaliza con la huida de los hombres superiores ante la visión del león riente y las palomas. Es decir, la animalidad

versidad Nacional Autónoma de México, México D.F., 3-6 de abril de 2006, en estos momentos en prensa en P. Rivero (comp.), El desafío de Nietzsche, México: Siglo XXI, 2009.

38. A este respecto, resulta sumamente claro el $\$ 57$ de MA II (KSA II 577-578), que comento en la conferencia mencionada en la nota anterior: «Si los animales nos reportan perjuicios (Schaden), entonces nos afanamos de todos los modos en su exterminio (Vernichtung), y los medios son con frecuencia bastante crueles sin que propiamente hablando lo queramos: es la crueldad de la irreflexión (die Grausamkeit der Gedankenlosigkeit). Si nos son útiles, los explotamos: hasta que una prudencia más sutil nos enseña que ciertos animales rinden bien con otro tratamiento, a saber, con el cuidado y la cría» (HH, trad. de A. Brotons Muñoz, Madrid: Akal, 1996, p. 140).

39. He trabajado este tema, en referencia a la interpretación heideggeriana de la animalidad en los mencionados cursos de 1929-1930, en «El oído de Heidegger en la cuestión de lo viviente animal»: Nombres. Revista de Filosofía XVIII/22 (2008), 103-113.

40. Za III, «Von alten und neuen Tafeln», KSA IV 246 (Za, Madrid: Alianza, 1997, p. 278). 
abre y cierra el Zaratustra IV. En toda esta parte de la obra, por otro lado, la figura del más feo de los hombres es casi como un eje desde el cual y hacia el cual giran los acontecimientos y el actuar de las otras figuras de hombres superiores. Recordemos que los hombres superiores son desesperados que, sabiendo de la muerte de Dios en sus diferentes formas (como muerte del Dios cristiano, del gobierno de los reyes, del valor de la ciencia, entre otros temas), son atraídos al mundo de Zaratustra ${ }^{41}$. El más feo de los hombres es quien se atribuye el asesinato de Dios, y Zaratustra lo encuentra en el reino de la muerte: él no es un hombre, sino «algo inexpresable», que no habla sino que «gorgotea» ${ }^{42}$. Zaratustra lo envía a su caverna, a hablar con sus animales, a su caverna que tiene junto a ella "cien agujeros y hendiduras para los animales que se arrastran, que revolotean y que saltan $»^{43}$. Del mismo modo, envía a hablar con sus animales al mendigo voluntario, que predica ante las vacas ${ }^{44}, \mathrm{y}$ al mago, a quien le sugiere pedir consejo de sus animales ${ }^{45}$. Y a todos los pretendidos hombres superiores los envía a su caverna como «huéspedes», les da hospitalidad en el ámbito de la extrañeza de lo viviente animal. Porque los animales de Zaratustra no son animales domésticos - y esto lo había destacado Heidegger-, no son los complacientes acompañantes del «hogar» (Heim), sino que testimonian lo Unheimliches, lo no familiar, la extrañeza. Allí, en el hogar, en la casa, en el lugar de la «más propia propiedad» para la filosofía moderna (el ámbito de la privacidad), allí, está lo extraño del animal. De algún modo, Zaratustra responde al grito de socorro con la hospitalidad ante lo extraño y en lo extraño, en esa caverna con agujeros para miles de animales ${ }^{46}$. Acoge a los desesperados ante la muerte de Dios, y los envía a quedarse con sus animales: ¿puede el hombre, acaso, «estar» con el animal de otro modo que en la familiaridad de la domesticidad? Sin embargo, en su caverna, con sus animales, Zaratustra les promete defenderlos de sus propios «animales salvajes» ${ }^{47}$. ¿Cuáles son estos animales salvajes? ¿Acaso el «animal interior» («das inwedige Gethier») ${ }^{48}$ al que se refiere la Genealogía de la moral, cuando habla de la mala conciencia como «alma animal»"

Zaratustra acoge a lo extraño en la extrañeza de su caverna habitada por la animalidad, y sin embargo, allí mismo, y aún antes de la fiesta del asno, Zaratustra les dice a esos desesperados que no es a ellos a quienes espera (tres veces les

41. Analizo cada una de estas figuras de hombre superior en mi artículo «De la risa disolvente a la risa constructiva: una indagación Nietzscheana», en M. B Cragnolini y G.Kaminsky, Nietzsche actual e inactual, Buenos Aires: Oficina de Publicaciones del CBC, 1996, vol. II, pp. 99-122.

42. En este gorgotear se hace visible lo que los humanismos han considerado siempre como el límite entre el humano y el animal: la posibilidad del lenguaje.

43. Za IV, «Der hässlichste Mensch», KSA IV 331 (p. 364).

44. Za IV, «Der freiwillige Bettler», KSA IV 337 (p. 369): «Y habla con mis animales acerca de la felicidad de los animales".

45. Za IV, «Der Zauberer», KSA IV 320 (p. 351): «Y pide consejo a mis animales».

46. Recordemos, en este punto, que para Nietzsche la hospitalidad tiene que ver con el mantenimiento de lo extraño, cf. M $\$ 319$, KSA III 226.

47. Za IV, «Die Begrüssung», KSA IV 348 (p. 381): «in meinem Reviere schütze ich Jeden vor seinen wilden Thieren». Trad. española

48. Za IV, «Von höheren Menschen», KSA IV 363 (p. 376); «Von der Wissenschaft», KSA IV 376 (p. 410).

49. GM II, $\mathbb{\$} 16, \mathrm{KSA}$ V 322. Recordemos que la conciencia se forma como «interiorización» de las fuerzas que no se pueden desplegar y que generan un mundo interior. 
dice «no», y les señala que es a otros a quienes aguarda), sino a «leones rientes» que deben venir («lachende Löwen müssen kommen») $)^{50}$.

El largo discurso previo a la cena — «Del hombre superior»—, habla precisamente de una transformación del modo de ser hombre: no se trata de mejorarlo, ni de conservarlo, sino de amar al ultrahombre ${ }^{51}$. Lo que se ama en el «hombre» no es, precisamente su «ser hombre», sino lo que no es, es decir, su ser tránsito y ocaso (Übergang, Untergang). Se ama del hombre lo que «deja de ser» hombre, lo que transita hacia otro modo de ser (el ultrahombre). Y el problema de los hombres que se acercaron a Zaratustra es que ellos no han sufrido por el hombre ${ }^{52}$ (es decir, por lo que significa el modo de ser hombre), sino por ellos mismos, por su pérdida del Dios-fundamento en los diferentes modos en que era adorado.

Si de lo que se trata es de «otro modo de ser», la presencia del animal en toda esta cuarta parte no puede estar señalando un simple «retorno» a la animalidad, sino algo diferente, tal vez la idea de cuestionar ese lugar adjudicado por los humanismos al animal, tanto en sí mismo como en el «animal humano» .

Después del discurso sobre el hombre superior, centrado en la necesidad de aprender a reír y bailar, Zaratustra vuelve a declarar su amor a sus animales «Yo os amo, animales míos» ${ }^{53}$, y también vuelve a hablar con ellos tras la canción del viajero y su sombra. Y precisamente lo que se hará evidente luego de la fiesta del asno es que los hombres superiores no saben reír, y el que parece más cercano a esta posibilidad entre ellos es «el más feo de los hombres».

Indiqué antes cómo esta figura de hombre superior está caracterizada casi desde la ausencia de lenguaje ("gorgotea», no habla), y desde una cierta monstruosidad. En efecto, él se califica a sí mismo como «demasiado rico, rico en cosas grandes, terribles, en las cosas más feas, más inexpresables» ${ }^{54}$. Si recordamos que el modo de ser del hombre de los humanismos, particularizado en el último hombre, es caracterizado en el «Prólogo» a la obra como «pequeño», carente de la posibilidad de crear porque se considera inventor de todo, incapaz de «un caos dentro de sí para dar a luz una estrella bailarina», este «hombre más feo» es el fracaso (como él mismo se califica) de ese modo de ser hombre "pequeño", en la medida de su «gran» fealdad. Él señala que mira a esas gentes pequeñas en dos modos animales: como el perro que mira al rebaño, y como la garza que observa estanques poco profundos. El más feo es figura entonces de la diferencia con respecto a lo mismo (el rebaño): quiebra esa mismidad de lo asegurado en los modos de los hombres pequeños con esa riqueza (terrible, inexpresable) que él es. Por eso, a diferencia de los últimos hombres, absolutamente contentos con su forma de vida de pequeños placeres y pequeños venenos, el más feo es para $\mathrm{Za}$ ratustra «alguien que ama mucho y que desprecia mucho» ${ }^{55}$. Pero, como indica Zaratustra, para el hombre es necesario aún despreciarse más profundamente.

50. Za IV, «Die Begrüssung», KSA IV 351 (p. 384). Es interesante destacar también que en una de las versiones que aparecen en los Póstumos de los capítulos de la cuarta parte del Za, el último capítulo («Das Zeichen» en la última versión) aparece titulado como «Der lachende Löwe», cf. FP III, 1884, 32[16] (KSA XI 416).

51. Za IV, «Von höheren Menschen», KSA IV 357 (p. 390).

52. Ibid., KSA IV 359 (p. 393).

53. Ibid., KSA IV 369 (p. 402).

54. Za IV, «Der hässlichste Mensch», KSA IV 329 (p. 362).

55. Ibid., KSA IV 332 (p. 364). 
Quienes aparecen en el IV Zaratustra son, como señalé, los pretendidos hombres superiores. Cuando Zaratustra dirige su discurso hacia ellos $^{56}$, señala su error de instalarse en el mercado, en el que no puede encontrar más compañeros que volatineros y cadáveres, y en el que no se puede hablar de nada diferente al último hombre, conforme y satisfecho con su modo de ser. Para hablar «de otro modo de ser», era necesario irse del mercado. En el mismo, la pregunta principal remite a la conservación: «Los más preocupados preguntan hoy: ‘Cómo se conserva el hombre?' Pero Zaratustra pregunta, siendo el primero y el único en hacerlo: ¿Cómo se supera [überwunden] el hombre?» ${ }^{57}$.

De entre estos hombres superiores, el más feo se destaca no sólo por haber asesinado a Dios y por ser, en esa mezcla de cosas terribles que lo constituyen, diferente del modo de ser hombre del último hombre, sino también por ser quien interpreta la fiesta del asno en un sentido diferente a sus compañeros. Aquel asno que traían consigo los reyes se convierte en la figura ante la que se arrodillan los hombres superiores cuando vuelven a ser piadosos. El papa jubilado justifica esta acción en una suerte de inversión del signo de la creencia: era difícil creer en un Dios espíritu, un dios-asno es algo más cercano y más tangible. De alguna manera, plantea lo que para Nietzsche es la típica actitud del nihilismo decadente, el que, no pudiendo hacer frente a la conflictividad y la tensión que la vida misma supone con sus múltiples matices, opta por una respuesta extrema ${ }^{58}$. Cada uno de los otros hombres superiores encuentra una razón justificadora de esta recaída en la vieja fe, pero el que aparece como «transformado» es el más feo de los hombres. Y es él quien señala que «con la risa se mata», y de alguna manera, hace pensar que la ceremonia es una parodia, un gesto irónico de despedida de las creencias en lo divino. Es por eso por lo que Zaratustra cree que ellos se han tornado alegres, y son capaces de «nuevas fiestas $»^{59}$. Y cuando salen de la caverna, es el hombre más feo el que indica que «merece la pena vivir en la tierra: un solo día, una sola fiesta con Zaratustra me ha enseñado a amar la tierra. ¿Esto era la vida? quiero decirle yo a la muerte. 'Bien! iOtra vez!' ${ }^{60}$ Es decir, el hombre más feo no sólo comprende el valor de la risa, sino también la necesidad del amor fati para aceptar ese devenir eternamente retornante que es la vida. Es entonces, después del agradecimiento a Zaratustra por parte de estos hombres, que el profeta persa recibe el llamado de la profunda medianoche, y puede escuchar la canción del eterno retorno, canción que señala que el dolor pasa, pero el placer pide eternidad.

Sin embargo, al día siguiente de esta noche de la fiesta del asno, y de este contento de Zaratustra con los hombres superiores, él advierte que ellos no son sus adecuados compañeros de viaje, porque aún no son el oído apto para escucharlo ${ }^{61}$. Y mientras los hombres superiores duermen, Zaratustra, «el despierto", está acompañado de sus animales: «Mis animales están despiertos, pues yo estoy

56. Za IV, «Von höheren Menschen», KSA IV 356 ss. (pp. 389 ss).

57. Ibid., KSA IV 357 (p. 390).

58. Esto es lo que señala de manera clara el 5[71] de los Nachgelassene Fragmente de 1887, escrito en Lenzer Heide el 10 de junio de 1887, al indicar que se revelarán como los más fuertes los más mesurados, los que no necesitan artículos de fe extremos, KSA XII 217 (FP IV p. 167).

59. Za IV, «Das Eselsfest», KSA IV 393 (p. 426).

60. Za IV, «Das Nachtwandler-Lied», KSA IV 396 (p. 429).

61. Za IV, «Das Zeichen», KSA IV 405 (p. 438). 
despierto ${ }^{62}$. Es entonces cuando arriban los pájaros «innumerables», que con sus aleteos caen como «una nube de amor ${ }^{63}$ sobre Zaratustra quien, al escabullirse de esa multitud de alas que lo acarician, siente que su mano se posa sobre la cabeza de un león. Y el león ${ }^{64}$, del mismo modo que las palomas, le da muestras de un amor vehemente, que impulsa a Zaratustra a decir que sus hijos están cerca. El amor de los animales anuncia, de algún modo, la llegada de sus hijos, es decir, el cumplimento de su obra.

Esa escena de amor entre Zaratustra, los pájaros y el león, que no se sabe cuanto dura, porque «para tales cosas no existe en la tierra tiempo alguno» ${ }^{65}$, es interrumpida por el despertar de los hombres superiores y su salida de la caverna, que es recibida por el rugido del león. Ante la visión del león, los hombres superiores gritan "con una sola boca» y huyen, desapareciendo, y dejando nuevamente solo a Zaratustra, ahora con más animales que al inicio del cuarto libro.

¿Por qué todo el IV Zaratustra nos lleva a la problemática del animal? Ya indiqué que sería ingenuo pensar en un «retorno» a la animalidad, como zona originaria, en el tránsito del hombre al ultrahombre. Sería tan ingenuo como plantear que la figura del niño en «De las tres transformaciones» remite a la infancia como estado ideal, originario, o que las referencias de Zaratustra al cuerpo como «gran razón» implican un retorno a la corporalidad, por inversión del privilegio concedido a la racionalidad ${ }^{66}$.

Sin embargo, es necesario notar que niños y animales están cercanos en varios aspectos ${ }^{67}$. Si ser hombre es ser sujeto, la «sujeción» a sí mismo del sujeto supone un fuerte aspecto sacrificial con respecto a la corporalidad (lo que se considera «animal» en el hombre) y a la infancia (ser hombre es ser adulto, decirle adiós a la infancia). El niño no representa en Nietzsche el ámbito de una zona originaria a la que retornar, sino, tal vez, el ámbito de lo posible. Mientras que el último hombre es el fin de posibilidad, en la voluntad de aseguramiento de lo real en la noción de fundamento fundante (la mismidad), el niño parecería indicar la diferencia de lo posible no necesariamente actualizado. Es decir, un modo de ser del existente humano diferente al modo de ser del sujeto representativo de la modernidad, que no puede relacionarse con su corporalidad y con el «animal

62. Ibid., KSA IV 405 (p. 439).

63. Ibid., KSA IV 406 (p. 439).

64. Para una interpretación de la figura del león en esta parte del Za, en direcciones diferentes a las que pretendo desarrollar en este artículo, véanse P. S. Loeb, "Zaratustra's Laughing Lions», en C. Davis Acampora y R. Acampora, A Nietzschean Bestiary. Becoming Animal Beyond Docile and Brutal, Lanham (MD): Rowman \& Littlefield, 2004, pp. 121-139, y W. M. Calder III, «The Lion Laughed»: Nietzsche-Studien 14 (1985). Michel Haar ("Les animaux de Zarathoustra. Forces fondamentales de la vie», en Par-delá le nihilism. Nouveaux essais sur Nietzsche, Paris: PUF, 1998, pp. 199-218) interpreta al león riente como "promesa» del ultrahombre, en tanto «síntesis de ternura y dureza».

65. Za IV, «Das Zeichen», KSA IV 407 (p. 440).

66. Para este tema remito a mi artículo «Ello piensa: la otra razón, la del cuerpo», en J. C. Cosentino y C. Escars (comps.), El problema económico. Yo-ello-super yo-sintoma, Buenos Aires: Imago Mundi, 2005, pp. 147-158.

67. Cuando el poeta argentino Juan L. Ortiz piensa en unir en una serie de relatos a «niños y bestias», de alguna manera tiene presente esta cercanía. Juan L. Ortiz, Los amiguitos. Cosas de niños, de animales y de paisajes, en Obra completa, introd. y notas de S. Delgado, Santa Fe: Universidad Nacional del Litoral, 22005. 
que es» si no es a través de los modos de la sujeción sacrificial que termina por aniquilar toda posibilidad de lo posible ${ }^{68}$.

\section{FINAL: LA ANIMALIDAD COMO MODO DE SER-CON}

Los hombres superiores huyen ante el león riente y las palomas, y Zaratustra queda nuevamente solo con sus animales. El tránsito por la animalidad que han hecho los hombres superiores en la adoración del asno parece desvelarse entonces como inadecuado, en la medida en que no han pensado esa «inversión» como una parodia ${ }^{69}$. Tal vez, solamente el más feo de los hombres ha podido considerar la fiesta del asno de esta manera; sin embargo, él también huye ante el león riente, poniendo de manifiesto que es aún «demasiado humano».

Compartiendo nuevamente la soledad con los animales, Zaratustra testimonia que es necesaria una «comunidad con lo viviente» que patentice otra relación con la vida, diferente a la propiciada por los humanismos. Si el espíritu, como señala el hombre superior en el modo del científico que estudia el cerebro de la sangüijuela, es la «vida que se saja a sí misma»" racional» supone herir a la vida en nosotros y en los otros, en la medida de la sujeción de la corporalidad que esa definición implica.

Sin embargo, la vida, que se da sus propias formas, necesita de esa escisión, tal como se señala en el tratado III de La genealogía de la moral ${ }^{71}$. No se trata, entonces, de plantear la posibilidad de una vida sin escisión (una supuesta totalidad exenta al espíritu) ni una pura escisión sin vida. En ese «entre» de la vida escindida, se hace necesario volver a pensar nuestra relación con la animalidad en la dirección de lo posible, y como un modo del ser-con que también somos con el viviente animal.

En esta dirección interpretativa, el león que ríe no sería la «figura» previa a la llegada del creador-niño (siguiendo «las tres transformaciones»), sino el anuncio de lo que acontece en el ocaso de los humanismos, cuando la animalidad puede patentizar, más que un ámbito de lo dominable, un modo de ser de la extrañeza (en lo viviente humano y no humano). «Hospedamos» a «lo» animal $\mathrm{y}$ «al» animal: eso habla de un modo del ser-con lo viviente que deconstruye los esquemas representativos de la alteridad y nos coloca, con-el-otro en la comunidad de la vida, como comunidad de lo posible.

68. Señalo la cuestión de la posibilidad para establecer nexos con la idea heideggeriana de Dasein como modo del existente humano, que significa una ruptura con respecto a la metafísica de la subjetividad. Es en este sentido, y en este modo de lo posible, como según mi parecer plantea G. Agamben, en la figura de Bartleby, que atraviesa toda su obra, la «potencia de no». Cf. mi artículo "Ciberespacio y potencia de suspensión", en G. Kaminsky et al., Bartleby: preferiría no. Lo bio-político, lo posthumano, Buenos Aires: La Cebra, 2008, pp. 61-72.

69. Aquí estoy considerando dos niveles de análisis de la «fiesta del asno»: en tanto «fiesta de adoración» (en su remisión a lo divino) y en tanto «adoración de la animalidad», como modo de retorno a la misma. En ambos casos, creo que esta supuesta inversión es presentada de manera paródica, para terminar «de matar a Dios».

70. Za IV, «Der Blutegel», KSA IV 312 (p. 344).

71. El tercer tratado de La genealogía de la moral plantea el problema del ideal ascético, tema en el que Nietzsche ha sabido ver, según mi parecer, la cuestión de la «inmunización», tal como la plantea la biopolítica contemporánea (cf. R. Esposito, Immunitas. Protezione e negazione della vita, Torino: Einaudi, 2002). 